\title{
Knowledge about Tuberculosis among Brazilians
} Lucas Scárdua Silva', Jhulia Gabriela Duarte de Sousa', Luísa Oliveira de Paiva', Orlando Roberto', Leonardo Filipini Pinheiro' and
Marcelo Fouad Rabahi ${ }^{12^{*}}$

${ }^{1}$ Federal University of Goiás, Faculty of Medicine, Goiânia, Goiás, Brazil

${ }^{2}$ Federal University of Goiás, Corner of 235 Street and 5th Avenue, Goiânia, Goiás, Brazil

\begin{abstract}
Background: Tuberculosisis an infectious disease responsible for 1.5 million deaths, worldwide, per year. Low levels of knowledge about TB are globally associated with a higher prevalence of latent TB infection and a low rate of treatment success. This study aimed to evaluate the level of TB knowledge of individuals at a recreational center in Goiânia, Goiás, Brazil.
\end{abstract}

Methods: We conducted 573 written structured interviews on recreational center frequentersin February and March, 2013, which included five close-ended questions and one open-ended question concerning TB. Data were analyzed with Epi Info 3.5.2.

Results: Percentages of patients who answered questions correctly were: $96.3 \%$ knew about TB (Q1); 48.5\% knew that TB is caused by a bacterial infection (Q2); 73.8\% knew that TB can be transmitted to people in contact with infected people (Q3); 75.4\% knew that TB can be transmitted via air or droplets (saliva) (Q4); $85.5 \% \mathrm{knew}$ that the main symptom of TB is cough (Q5); and $96.1 \%$ knew that TB is a curable disease (Q6).

Conclusion: Overall, a quarter of the population was not aware of the main symptoms, transmission mode, and transmissibility of TB. In order to control TB infection and prevent its spread, emphasis should be placed on increasing awareness of this disease among individuals.

Keywords: Tuberculosis; Structured interview; Epidemiology

\section{Introduction}

Tuberculosis (TB) is an infectious disease caused by Mycobacterium tuberculosis and is the main infectious cause of deaths worldwide, especially among those with a low economic status $[1,2]$. TB is a curable disease and, in some countries, TB treatment has a success rate of $90 \%$ [3]. Given the TB treatment efficacy, high rates of TB infection remains an apparent paradox. According to Centers for Disease Control and Prevention, some subgroups of individuals (i.e. HIV positive individuals, alcohol consumers, and cigarette smokers) are at a greater risk of contracting the disease [4]. In addition, incorrect treatment, such as treatment abandonment $[5,6]$, results in poor disease control.

Moreover, studies demonstrate that disease awareness can prevent therapy abandonment up to $90 \%$ of the time [7]. In addition, a higher level of education has been shown to translate to a higher level of knowledge of TB. Specifically, the 20 highest rates of TB are in countries such as Zimbabwe, Cambodia, and Afghanistan (but also Brazil, China, and Russia), which have low rates of "average years of schooling" and "expected years of schooling" [8,9]. In addition, literature shows that individuals with TB have a lower level of education than those without TB [10]. Reinforcing the importance of teaching people about Tuberculosis, World Health Organization created the Stopping TB Operational Strategy, which focused on TB education as one of its main objectives [11].

This study aimed to analyze the TB awareness in individuals in Goiânia (a Brazilian city, capital of Goiás State). This analysis was conducted through structured interviews consisting of six questions to evaluate participants' knowledge of cognizance, cause, transmission mode, transmissibility, symptoms, and treatment of TB.

\section{Material and Methods}

This cross-sectional study included 573 frequenters of a recreational center in Goiânia, Goiás, Brazil, and was conducted during months of February and March, 2013. Six questions concerning common pulmonary TB were included, covering the following topics: cognizance, cause, transmission mode, transmissibility, main symptoms, and treatment regimen (Figure 1). Correct answers were as follows: Yes (1), Bacteria (2), Yes (3), through air or droplets (saliva) (4), Cough (5), and Yes (6).We analyzed the results, comparing percentage of correct answers with a hypothetical $100 \%$ percentage result. All data were collected, tabulated, and analyzed using Microsoft Excel 2010/2013 from Microsoft, Redmond, Washington and Epi Info 3.5.2 from CDC, DeKalb County, Georgia, USA.

\section{Ethics}

We observed the principles of autonomy, beneficence, nonmaleficence, and justice requested by Brazilian Regulatory Authorities.

\section{Results}

Participants answered 573 structured interviews: 551 (96.3\%) individuals had knowledge of TB. With regards to answering questions pertaining to the cause of $\mathrm{TB}, 278(48.5 \%)$ individuals referred to bacteria; 110 (19.2\%) referred to smoking; 85 (14.8\%) did not know the

*Corresponding author: Marcelo Fouad Rabahi, MD, Federal University of Goiás,corner of 235 Street and 5th Avenue, Goiânia, Goiás, Brazil, Tel: 556281210611; E-mail: mfrabahi@gmail.com

Received January 15, 2016; Accepted February 09, 2016; Published February 12, 2016

Citation: Silva LS, de Sousa JGD, de Paiva LO, Roberto O, Pinheiro LF, et al (2016) Knowledge about Tuberculosis among Brazilians. J Clin Respir Dis Care 2: 106. doi: $10.4172 / 2472-1247.1000106$

Copyright: @ 2016 Silva LS, et al. This is an open-access article distributed under the terms of the Creative Commons Attribution License, which permits unrestricted use, distribution, and reproduction in any medium, provided the original author and source are credited. 


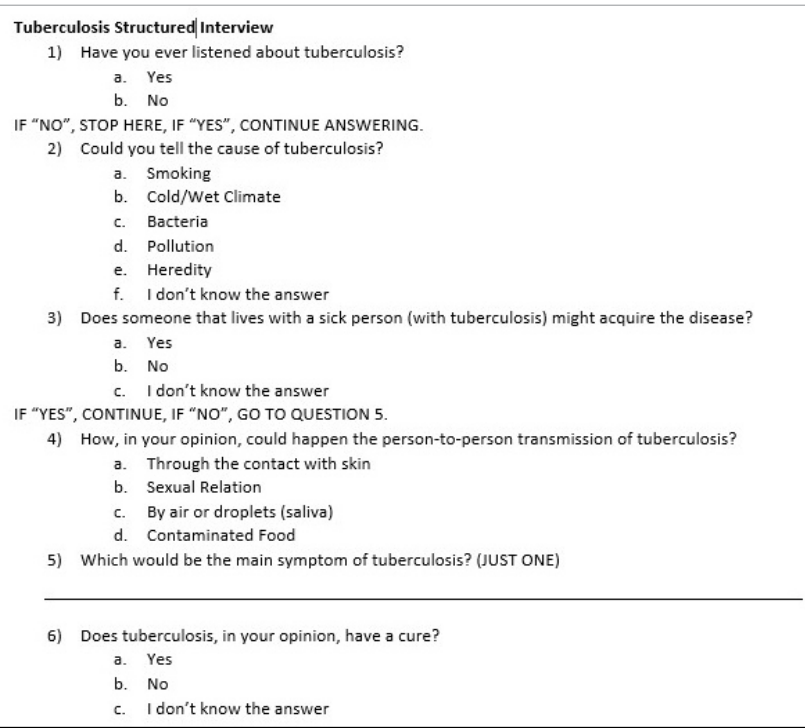

Figure 1: Tuberculosis structured interviewapplied in the population of Goiânia, Goiás, Brazil. Right answers were, considering a common pulmonary TB, respectively: Yes (1), Bacteria (2), Yes (3), By air or droplets (saliva) (4), Cough (5), Yes (6).

answer; 25 (6.1\%) answered other items such as humidity, pollution, or heredity; and 65 (11.3\%) gave no answer.

About transmission mode, 423 (73.8\%) participants believed it to be through air; $14(2.4 \%)$, through skin contact; $3(0.5 \%)$, via sexual transmission; and $10(1.7 \%)$, due to contaminated food.Additionally, 123 (21.5\%) did not know the answer.

When discussing transmissibility, from total (573), 432 (75.4\%) participants answered that an individual could be infected by living with an infected individual, $71(12.4 \%)$ stated that transmission was not possible, 45 (7.9\%) did not know the answer, and 25 (4.3\%) left the item blank.

Patients, 492 (85.5\%), cited cough as the main symptom. From these, 75 (15.2\%) emphasized an association of "long term cough" with TB. Participants also cited other types of cough, such as bloody cough by $20(4.0 \%)$, dry cough by $14(8.2 \%)$, and cough with expectoration by $10(2.0 \%) ; 373(75.8 \%)$ provided no specific characteristic. Other symptoms were also cited, including chest pain by $3(0.5 \%)$, shortness of breath by $5(0.9 \%)$, and fever by $9(1.6 \%)$.

In response to the question concerning treatment, for 551 (96.1\%) individuals TB is curable, for $20(3.5 \%)$ TB is not curable, and $2(0.4 \%)$ did not know the answer. Figure 2 presents the percentage of right and wrong answers.

\section{Discussion}

Considering the complex epidemiology of $\mathrm{TB}$, which resulted in 1.5 million deaths worldwide in 2014, determining how efficient and specific education on TB can be delivered, and what is important for non-professional population to learn, remains unclear [12].

Of all patients, $96.3 \%$ knew about TB and $96.1 \%$ knew TB is a curable disease. This is likely due to TB Control National Programme from Brazilian Ministry of Health [13] that proposes actions to control TB through education and communication. Questions 1 and 6 were considered non-specific as they could be easily guessed.

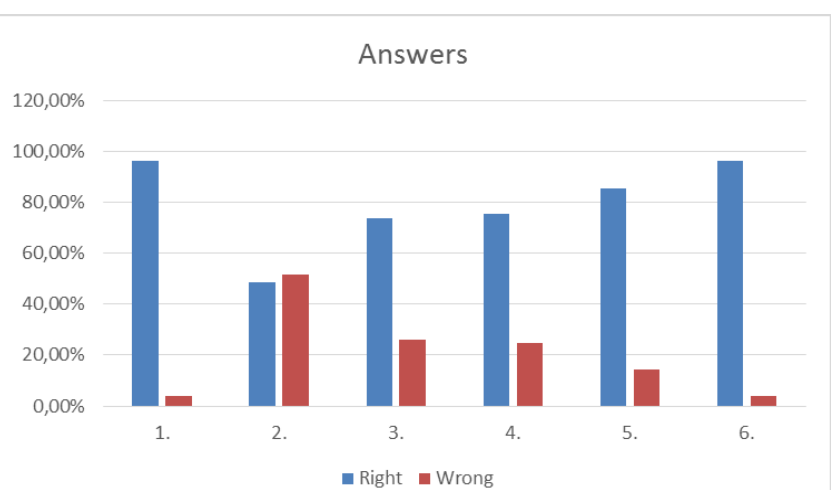

Figure 2: The percentage of right and wrong answers per question. Right answers: Yes $96.30 \%$ (1), Bacteria $48.50 \%$ (2), Yes $73.80 \%(3)$, By air or droplets $75.40 \%$ (saliva) (4), Cough $85.50 \%$ (5), Yes $96.10 \%(6)$.

Question 2 had the lowest correct response rate $(48.5 \%$ were correct), and answers such as pollution only accounted for $6.1 \%$ of answers. In fact, this information is not a priority for general population; only healthcare professionals are required to have this knowledge. Main symptoms, transmissibility and transmission mode of TB (questions 3 , 4 , and 5) are the essential information for patients.

Finally, a worrying fact is that only $24.2 \%$ of who answered 'cough' were able to characterize it. Considering TB clinical diagnosis, long-term cough specificity is $95 \%$ and any-term cough specificity is $80 \%$. Soon, long-term cough strongly suggests TB infection. Lack of awareness may prevent patients from seeking assessment from a health care professional, delaying TB diagnosis and leading to higher rates of morbidity, mortality, and transmissibility, all of which are burdens on health care systems and would increase TB prevalence [14].

\section{Conclusion}

Approximately $80 \%$ of the studied population had a good comprehension of essential questions. However, in order to change $\mathrm{TB}$ rates, a higher level of knowledge concerning main symptoms, transmission mode, and transmissibility is important. Emphasis in increasing awareness among individuals may help in controlling TB.

\section{Acknowledgements}

None.

\section{References}

1. Acosta LMW, Bassanesi SL (2014) The Porto Alegre paradox: social determinantsandtuberculosisincidence. RevBrasEpidemiol 17: 88-101.

2. http://refbooks.msf.org/msf_docs/en/tuberculosis/tuberculosis_en.pdf.

3. http://data.worldbank.org/indicator/SH.TBS.CURE.ZS.

4. http://www.cdc.gov/tb/topic/basics/risk.htm.

5. Silva PF, Moura GS, Caldas AJM (2014) Factors associated with pulmonary TB treatment dropout in Maranhão State, Brazil, from 2001 to 2010. CadSaude Publica 30: 1745-1754.

6. Temoteo RCA, Luna FDT, Lacerda SNB, Abreu LC, Fonseca FLA, et al. (2015) Accession to tuberculosis treatment: individual and social vulnerability elements. Int Arch Med 8.

7. Silva EA, Anjos UU, Nogueira JA (2014) Predictive model to the tuberculosis treatment abandonment. Saude debate 38: 200-209. 
Citation: Silva LS, de Sousa JGD, de Paiva LO, Roberto O, Pinheiro LF, et al. (2016) Knowledge about Tuberculosis among Brazilians. J Clin Respir Dis Care 2: 106. doi: 10.4172/2472-1247.1000106

Page 3 of 3

8. http://apps.who.int/iris/bitstream/10665/191102/1/9789241565059_eng.pdf.

9. http://hdr.undp.org/en/content/table-1-human-development-index-and-itscomponents.

10. Pereira AGL, Medronho RA, Escosteguy CC, Valencia LIO, Figueiredo MA, et al. (2015) Spatial distribution and socioeconomic context of tuberculosis in Rio de Janeiro, Brazil. RevSaude Publica 49: 48.
11. http://www.stoptb.org/assets/documents/about/OperationalStrategy2013-2015.pdf.

12. http://www.who.int/features/factfiles/tb_facts/en/index7.html.

13. http://bvsms.saude.gov.br/bvs/publicacoes/ProgramaTB.pdf.

14. http://www.who.int/tb/Review2Accuracyofscreeningtests.pdf. 